\title{
Analisis Potensi dan Daya Saing Sektor Pertanian di Kabupaten Tabanan
}

\author{
Analysis of Superior Potential and Competitiveness of the Agricultural Sector \\ in Tabanan Regency \\ Ni Komang Ayu Fitri Adi Cahyani *) \\ Dwi Putra Darmawan \\ Gede Mekse Korri Arisena
}

Fakultas Pertanian, Universitas Udayana, Bali, Indonesia

${ }^{*}$ Email: ayu.fitri1498@gmail.com

\begin{abstract}
The agricultural sector in Tabanan Regency not only plays a role in food security, but also contributes significantly to sources of income. During the last five years the agricultural sector in Tabanan Regency has also contributed significantly to the GRDP of Tabanan Regency. The purpose of this study is to identify the superior potential of the agricultural sector in Tabanan Regency and to identify the competitiveness of the agricultural sector in Tabanan Regency. This study uses secondary data sourced from the Central Statistics Agency (BPS) of Tabanan Regency and Bali Province. There are two analyzes used in this study, namely Location Quotient (LQ) analysis and Shift Share analysis. The results of research using Location Quotient (LQ) analysis show that the agricultural sector is included in the category of leading sectors in Tabanan Regency. This is indicated by the Location Quotient (LQ) value that is greater than one. While the results of the study using Shift Share analysis show that the agricultural sector in Tabanan Regency is included in the category of sectors that have fast competitiveness compared to reference areas, this is because the value of Differential Shift shows a positive value.
\end{abstract}

Keywords : Superior potential, competitiveness, and the agricultural sector.

\section{ABSTRAK}

Sektor pertanian di Kabupaten Tabanan tidak hanya berperan terhadap ketahanan pangan, tetapi juga memberikan andil yang cukup besar terhadap sumber pendapatan. Selama lima tahun terakhir sektor pertanian di Kabupaten Tabanan juga telah memberikan kontribusi yang cukup tinggi terhadap PDRB Kabupaten Tabanan. Tujuan dari penelitian ini yaitu untuk mengidentifikasi potensi unggulan sektor pertanian di Kabupaten Tabanan dan mengidentifikasi daya saing sektor pertanian di Kabupaten Tabanan. Penelitian ini menggunakan data sekunder yang bersumber dari Badan Pusat Statistik (BPS) Kabupaten Tabanan dan Provinsi Bali, terdapat dua analisis yang digunakan dalam penelitian ini yaitu 
analisis Location Quotient (LQ) dan analisis Shift Share. Hasil penelitian dengan menggunakan analisis Location Quotient (LQ) menunjukan bahwa sektor pertanian masuk dalam kategori sektor unggulan di Kabupaten Tabanan. hal ini ditunjukan oleh nilai Location Quotient (LQ) yang lebih besar dari satu. Sedangkan hasil penelitian menggunakan analisis Shift Share menunjukan bahwa sektor pertanian di Kabupaten Tabanan masuk dalam kategori sektor yang memiliki daya saing yang cepat dibandingkan dengan daerah refrensi, hal ini karena nilai Differential Shift yang menunjukan nilai positif.

Kata kunci : Potensi unggulan, daya saing, dan sektor pertanian

\section{PENDAHULUAN}

\section{Latar Belakang}

Sektor pertanian merupakan salah satu leading sector atau sektor unggulan yang dapat dijadikan lokomotif pemulihan ekonomi. Sektor unggulan perlu ditentukan oleh suatu daerah karena setiap daerah mempunyai karakter yang berbeda baik dari sisi kesuburan lahan, letak geogerafis, sumber daya manusia, dan sarana-prasarana yang ada. Identifikasi dan klasifikasi sektor diperlukan untuk memberikan gambaran sektor mana yang aktifitasnya menjadi basis perekonomian atau unggulan, potensial, sedang berkembang dan mana pula yang tertinggal, sehingga dapat dilakukan penentuan sektor prioritas. Berdasarkan sektor basis, pemerintah daerah dapat membuat kebijakan dan strategi pembangunan agar pembangunan sektor perekonomian dapat berjalan dengan optimal (Hardyanto dalam Wiguna dan Budhi, 2019). Kabupaten atau kota di Provinsi Bali masing-masing memiliki keunggulan yang tergantung pada letak wilayah, sumber daya alam dan sumber daya manusia yang dimiliki. Kabupaten Tabanan merupakan salah satu kabupaten yang ada di Provinsi Bali, yang memiliki 10 Kecamatan dengan luas wilayah seluas $839,33 \mathrm{~km}^{2}$ atau $14,90 \%$ dari luas Provinsi Bali. Laju pertumbuhan ekonomi kabupaten atau kota di Provinsi Bali pada tahun 2019 menunjukkan Kabupaten Tabanan berada diposisi ke empat dari Sembilan kabupaten yang ada. Kabupaten Tabanan pada tahun 2015 mempunyai laju pertumbuhan ekonomi yang cukup besar yaitu sebesar 6,19 persen dan tahun 2016 memiliki laju pertumbuhan ekonomi sebesar 6,14 persen. Pada tahun 2017 laju pertumbuhan ekonomi Kabupaten Tabanan mengalami penurunan sebesar 5,37 persen. Pada tahun 2018 laju pertumbuhan ekonomi Kabupaten tabanan mengalami kenaikan sebesar 5.73 persen, dan pada tahun berikutnya yaitu tahun 2019 laju pertumbuhan ekonomi Kabupaten Tabanan mengalami penurunan sebesar 5,60 persen (BPS Provinsi Bali, 2019). Terjadinya penururan laju pertumbuhan ekonomi di Kabupaten Tabanan tidak terlepas dari sektor-sektor yang berkontribusi dalam pertumbuhan ekonomi Kabupaten Tabanan. 


\section{RumusanMasalah}

Rumusan masalah dari penelitian ini adalah:

1. Apakah sektor pertanian menjadi sektor unggulaan di Kabupaten Tabanan?

2. Bagaimana daya saing sektor pertanian di Kabupaten Tabanan?

\section{Tujuan Penelitian}

Tujuan penelitian adalah sebagai berikut.

1. Mengidentifikasi potensi unggulan sektor pertanian di Kabupaten Tabanan.

2. Untuk mengetahui daya saing sektor pertanian di Kabupaten Tabanan.

\section{METODE PENELITIAN}

\section{Lokasi dan Waktu Penelitian}

Penelitian ini dilaksanakan di Kabupaten Tabanan, Provinsi Bali. Waktu penelitian dilakukan pada bulan Oktober - November 2020. Pemilihan lokasi penelitian dilakukan secara sengaja atas pertimbangan tertentu.

\section{Data dan Metode Pengumpulan}

Jenis data yang digunakan dalam penelitian ini yaitu data kuantitatif dan kualitatif. Data kuantitatif yang berupa data Produk Domestik Regional Bruto Kabupaten Tabanan dan Provinsi Bali pada tahun 2012-2019, sedangkan data kualitatif berupa gambaran umum seperti letak geografis lokasi penelitian.

Data sekunder adalah data yang diperoleh tidak langsung yang bersumber dari jurnaljurnal, artikel terkait, dan BPS. Data sekunder tersebut terdiri dari PDRB Kabupaten Tabanan dan PDRB Provinsi Bali.

Metode pengumpulan data yang digunakan dalam penelitian ini ada dua yaitu: 1). Dokumentasi merupakan metode pengumpulan data dengan cara mengumpulkan catatan, arsip, dan lain sebagainya. 2). Studi kepustakaan merupakan pengumpulan data dengan mencari sumber-sumber di luar seperti buku, literature, hasil penelitian sejenis, dan media lain yang berkaitan dengan penelitian.

\section{Variabel Penelitian dan Pengukuran}

Variabel dalam penelitian ini lebih jelasnya dapat dilihat pada Tabel 1 berikut : 
Tabel 1. Jenis dan pengukuran variabel

\begin{tabular}{llc}
\hline \multicolumn{1}{c}{ Variabel } & \multicolumn{1}{c}{ Indikator } & Pengukuran \\
\hline Sektor Unggulan & 1). PDRB sub sektor-sub sektor pertanian & Rasio \\
& $\begin{array}{l}\text { Kabupaten Tabanan dan Provinsi Bali } \\
\text { ADHK tahun 2012 -2019 }\end{array}$ & \\
\hline Daya saing & $\begin{array}{l}\text { 1. PDRB sektor awal tahun dan akhir tahun } \\
\text { 2. PDRB sektor nasional pada awal tahun } \\
\text { dan akhir tahun }\end{array}$ & Rasio \\
\hline
\end{tabular}

\section{Metode Analisis}

\section{Analisis Location Quotient}

Analisis Location Quotient (LQ) digunakan untuk mengetahui tujuan satu pada penelitian ini. Alat analisis Location Quetiont dimaksudkan untuk mengidentifikasi dan merumuskan komposisi dan pergeseran sektor basis suatu wilayah dengan menggunakan data Produk Domestik Regional Bruto (PDRB) sebagai indikator pertumbuhan wilayah (Adisasmita dalam Pantow et al., 2015).

Analisis Location Quotient (LQ) merupakan salah satu alat analisis yang dapat digunakan untuk mengetahui sektor basis dan non basis yang berada di Kabupaten Tabanan. Secara sistematis perhitungan LQ dinyatakan sebagai berikut:

$$
L Q=\frac{V i k / V k}{V i p / V p}
$$

Keterangan:

LQ = Nilai Location Quotient (LQ).

Vik = PDRB sektor i di Kabupaten Tabanan

$\mathrm{Vk}=$ PDRB total di Kabupaten Tabanan

Vip $=$ PDRB sektor i di Provinsi Bali

$\mathrm{Vp}=$ PDRB total di Provinsi Bali

\section{Analisis Shift Share}

Analisis shift-share digunakan untuk menganalisis dan mengetahui tujuan dua dari penelitian ini yaitu daya saing sektor pertanian di Kabupaten Tabanan. Analisis shift share merupakan salah satu teknik yang sangat berguna untuk menganalisis perubahan struktural ekonomi daerah dibandingkan dengan struktur ekonomi diatasnya.

Formulasi yang digunakan untuk analisis shift-share pada penelitian ini adalah :

a). Dampak riil pertumbuhan ekonomi :

$\mathrm{Dij}=\mathrm{Nij}+\mathrm{Mij}+\mathrm{Cij}$ atau $\mathrm{Dij}=\mathrm{Eij}^{*}-\mathrm{Eij}$

b). Pengaruh pertumbuhan ekonomi 


$$
\mathrm{Nij}=\text { Eij } \mathrm{x} \text { rn }
$$

c) Pergeseran proposional (Pertumbuhan proposional) :

$$
\text { Mij }=\operatorname{Eij}(\text { rin }- \text { rn) }
$$

d). Pengaruh kebasis kompetitif :

$$
\mathrm{Cij}=\mathrm{Eij}(\mathrm{rij}-\mathrm{rin})
$$

Keterangan :

Dij : Perubahan suatu Variabel regional sektor i di wilayah j dalam kurun waktu tertentu

Nij : Komponen pertumbuhan Provinsis Bali sektor i di wilayah Provinsi Bali

Mij : Bauran industri sektor i di wilayah Kabupaten Tabanan

Cij : Keunggulan kompetitif sektor i di wilayah Kabupaten Tabanan

$\mathrm{E}^{*} \mathrm{ij}$ : PDRB sektor i di wilayah Kabupaten Tabanan pada tahun akhir analisis

Eij : PDRB sektor i diwilayah Kabupaten Tabanan pada tahun dasar

rn : Laju pertumbuhan Provinsi Bali

rin : Laju pertumbuhan sektor i wilayah Provinsi Bali

rij : Laju pertumbuhan sektor i di wilayah Kabupaten Tabanan

\section{HASIL DAN PEMBAHASAN}

\section{Potensi Unggulan Sektor Pertanian di Kabupaten Tabanan}

Apabila nilai $L Q>1$ maka dinyatakan sektor unggulan, dimana yang artinya peranan suatu sektor dalam perekonomian Kabupaten Tabanan lebih besar dari pada peranan sektor tersebut dalam perekonomian Provinsi Bali, dan apabila nilai LQ $<1$ maka dinyatakan sektor non unggulan dimana yang artinya peranan suatu sektor dalam perekonomian di Kabupaten Tabanan lebih kecil dari pada peranan sektor tersebut dalam perekonomian Provinsi Bali. Adapun hasil dari analisis Location Quotient (LQ) Kabupaten Tabanan untuk mengetahui sektor yang mempengaruhi perekonomian tahun 2010-2019 dapat dilihat pada tabel berikut:

Berdasarkan hasil perhitungan Analisis Location Quetient (LQ) nilai sektor pertanian tahun 2010-2019 menunjukkan nilai LQ>1 Yang artinya sektor pertanian dikategorikan sebagai sektor unggulan. Sektor pertanian di Kabupaten Tabanan masuk kedalam sektor unggulan karena sektor pertanian di Kabupaten Tabanan sudah mampu mengekspor komoditi unggulannya yaitu manggis. 
Tabel 2. Sektor Unggulan di Kabupaten TabananTahun 2010-2019

\begin{tabular}{|c|c|c|c|c|c|c|c|c|c|c|c|c|}
\hline \multirow{2}{*}{ Kategori Sektor } & \multicolumn{10}{|c|}{ Nilai LQ } & \multirow{2}{*}{$\begin{array}{c}\text { Rata-rata } \\
\text { LQ }\end{array}$} & \multirow{2}{*}{ Ket } \\
\hline & 2010 & 2011 & 2012 & 2013 & 2014 & 2015 & 2016 & 2017 & 2018 & 2019 & & \\
\hline $\begin{array}{l}\text { Pertanian, } \\
\text { Kehutanan, dan } \\
\text { Perikanan }\end{array}$ & 1.47 & 1.48 & 1.51 & 1.52 & 1.51 & 1.49 & 1.52 & 1.54 & 1.56 & 1.57 & 1.52 & Unggulan \\
\hline $\begin{array}{l}\text { Pertanmbangan dan } \\
\text { Penggalian }\end{array}$ & 1.05 & 1.06 & 1.06 & 1.06 & 4.29 & 1.11 & 1.10 & 1.16 & 1.21 & 1.25 & 1.44 & Unggulan \\
\hline Industri Pengolahan & 0.85 & 0.86 & 0.86 & 0.86 & 0.86 & 0.89 & 0.91 & 0.92 & 0.91 & 0.90 & 0.88 & $\begin{array}{c}\text { Non } \\
\text { Unggulan }\end{array}$ \\
\hline $\begin{array}{l}\text { Pengadaan Listrik } \\
\text { dan Gas }\end{array}$ & 0.53 & 0.53 & 0.52 & 0.53 & 0.50 & 0.50 & 0.47 & 0.47 & 0.47 & 1.00 & 0.55 & $\begin{array}{c}\text { Non } \\
\text { Unggulan }\end{array}$ \\
\hline $\begin{array}{l}\text { Pengadaan Air, } \\
\text { Pengelolaan Sampah, } \\
\text { Limbah }\end{array}$ & 0.83 & 0.83 & 0.83 & 0.84 & 0.84 & 0.84 & 0.83 & 0.83 & 0.86 & 0.86 & 0.84 & $\begin{array}{c}\text { Non } \\
\text { Unggulan }\end{array}$ \\
\hline Kontruksi & 1.04 & 1.04 & 1.04 & 1.05 & 1.05 & 1.07 & 1.07 & 1.07 & 1.02 & 1.01 & 1.05 & Unggulan \\
\hline $\begin{array}{l}\text { Perdagangan Besar } \\
\text { dan Eceran; Reparasi } \\
\text { Mobil dan Sepeda } \\
\text { Motor } \\
\end{array}$ & 0.96 & 0.96 & 0.95 & 0.96 & 0.97 & 0.97 & 0.98 & 0.97 & 0.97 & 0.96 & 0.97 & $\begin{array}{c}\text { Non } \\
\text { Unggulan }\end{array}$ \\
\hline $\begin{array}{l}\text { Transportasi dan } \\
\text { Pergudangan }\end{array}$ & 0.24 & 0.23 & 0.23 & 0.23 & 0.24 & 0.24 & 0.24 & 0.24 & 0.24 & 0.24 & 0.24 & $\begin{array}{c}\text { Non } \\
\text { Unggulan }\end{array}$ \\
\hline $\begin{array}{l}\text { Penyediaan } \\
\text { Akomodasi dan } \\
\text { Makan Minum } \\
\end{array}$ & 0.94 & 0.94 & 0.93 & 1.00 & 0.94 & 0.94 & 0.93 & 0.93 & 0.94 & 0.94 & 0.94 & $\begin{array}{c}\text { Non } \\
\text { Unggulan }\end{array}$ \\
\hline $\begin{array}{l}\text { Informasi dan } \\
\text { Komunikasi }\end{array}$ & 1.01 & 1.01 & 1.01 & 1.02 & 1.02 & 1.02 & 1.03 & 1.02 & 1.01 & 0.99 & 1.01 & Unggulan \\
\hline $\begin{array}{l}\text { Jasa Keuangan dan } \\
\text { Asuransi }\end{array}$ & 0.85 & 0.85 & 0.85 & 0.86 & 0.88 & 0.85 & 0.84 & 0.84 & 0.84 & 0.85 & 0.85 & $\begin{array}{c}\text { Non } \\
\text { Unggulan }\end{array}$ \\
\hline Real Estate & 1.21 & 1.21 & 1.21 & 1.22 & 1.22 & 1.24 & 1.21 & 1.21 & 1.24 & 1.23 & 1.22 & Unggulan \\
\hline Jasa Perusahaan & 0.90 & 0.91 & 0.90 & 0.91 & 0.92 & 0.92 & 0.92 & 0.93 & 0.92 & 0.94 & 0.92 & $\begin{array}{c}\text { Non } \\
\text { Unggulan }\end{array}$ \\
\hline $\begin{array}{l}\text { Pemerintahan, } \\
\text { Pertahanan dan } \\
\text { Jaminan Sosial Wajib }\end{array}$ & 1.83 & 1.89 & 1.38 & 1.39 & 1.40 & 1.41 & 1.41 & 1.42 & 1.44 & 1.50 & 1.51 & Unggulan \\
\hline Jasa Pendidikan & 0.34 & 0.34 & 0.34 & 0.34 & 0.34 & 0.35 & 0.35 & 0.35 & 0.35 & 0.35 & 0.35 & $\begin{array}{c}\text { Non } \\
\text { Unggulan }\end{array}$ \\
\hline $\begin{array}{l}\text { Jasa Kesehatan dan } \\
\text { Kegiatan Sosial }\end{array}$ & 1.04 & 1.05 & 1.04 & 1.05 & 1.06 & 1.07 & 1.05 & 1.07 & 1.06 & 1.07 & 1.06 & Unggulan \\
\hline Jasa lainnya & 1.20 & 1.20 & 1.19 & 1.20 & 1.21 & 1.20 & 1.19 & 1.22 & 1.24 & 1.25 & 1.21 & Unggulan \\
\hline
\end{tabular}

Sumber : BPS Kabupaten Karangsem (data diolah menggunakan metode LQ) 


\section{Daya Saing Sektor Pertanian Di Kabupaten Tabanan}

Berikut adalah hasil Analisis Shift Share sektor pertanian di Kabupaten Tabanan tahun 2010-2019.

Tabel 3. Daya Saing Sektor Pertanian di Kabupaten Tabanan Tahun 2010-2019

\begin{tabular}{|c|c|c|c|c|}
\hline KATEGORI PDRB & $\begin{array}{l}\text { National } \\
\text { share }\end{array}$ & $\begin{array}{l}\text { Proportional } \\
\text { Shift }\end{array}$ & $\begin{array}{l}\text { Differential } \\
\text { Shift }\end{array}$ & Total \\
\hline $\begin{array}{l}\text { Pertanian, Kehutanan, } \\
\text { dan Perikanan }\end{array}$ & 1738307.1 & -928378.938 & 114293.63 & 924221.83 \\
\hline $\begin{array}{l}\text { Pertambangan dan } \\
\text { Penggalian }\end{array}$ & 87469.973 & -57109.2141 & 23062.691 & 53423.45 \\
\hline Industri Pengolahan & 410964.49 & -88058.9333 & 26172.517 & 349078.07 \\
\hline $\begin{array}{l}\text { Pengadaan Listrik dan } \\
\text { Gas }\end{array}$ & 7420.2869 & 266.817387 & -2207.034 & 5480.07 \\
\hline $\begin{array}{l}\text { Pengadaan Air, } \\
\text { Pengolahan Sampah, } \\
\text { Limbah }\end{array}$ & 14597.364 & -6407.6867 & 206.40255 & 8396.08 \\
\hline Konstruksi & 632790.47 & 208660.8485 & -83890.28 & 757561.04 \\
\hline $\begin{array}{l}\text { Perdagangan Besar dan } \\
\text { Eceran; Reparasi Mobil } \\
\text { dan Sepeda Motor }\end{array}$ & 571240.04 & 110368.4808 & -30793 & 650815.52 \\
\hline $\begin{array}{l}\text { Transportasi dan } \\
\text { Pergudangan }\end{array}$ & 123213.39 & -3831.60667 & -5898.307 & 113483.48 \\
\hline $\begin{array}{l}\text { Penyediaan Akomodasi } \\
\text { dan Makan Minum }\end{array}$ & 1233774.8 & 154047.0947 & -86573.24 & 1301248.62 \\
\hline $\begin{array}{l}\text { Informasi dan } \\
\text { Komunikasi }\end{array}$ & 433999.25 & 145153.4163 & -49878.61 & 529274.05 \\
\hline $\begin{array}{l}\text { Jasa Keuangan dan } \\
\text { Asuransi }\end{array}$ & 230029.66 & 30954.24185 & -16825.83 & 244158.07 \\
\hline Real Estate & 402385.6 & -54460.8414 & -5241.502 & 342683.26 \\
\hline Jasa Perusahaan & 70219.932 & -2834.19659 & 1759.6346 & 69145.37 \\
\hline $\begin{array}{l}\text { Administrasi } \\
\text { Pemerintahan, } \\
\text { Pertahanan dan } \\
\text { Jaminan Sosial Wajib }\end{array}$ & 527378.89 & -13370.6684 & 74996.914 & 589005.14 \\
\hline Jasa Pendidikan & 111641.67 & 41320.71936 & 2243.5549 & 155205.94 \\
\hline $\begin{array}{l}\text { Jasa Kesehatan dan } \\
\text { Kegiatan Sosial }\end{array}$ & 142350.87 & 71908.33022 & -66.56539 & 214192.63 \\
\hline Jasa Lainnya & 129157.99 & 20033.85507 & 7370.9076 & 156562.75 \\
\hline Jumlah & 6866941.776 & -371738.281 & -31268.1167 & 6463935.37 \\
\hline
\end{tabular}

Sumber : BPS Kabupaten Tabanan (data diolah)

Hasil analisis sektor pertanian di Kabupaten Tabanan menggunakan metode analisis Shift Share menunjukkan bahwa sektor pertanian di Kabupaten Tabanan tumbuh lambat dan 
memiliki daya saing yang cepat, hal ini dapat dilihat dari nilai Proportional Shift yang menunjukan nilai negative dan Differential Shift yang menunjukan nilai positif.

\section{SIMPULAN DAN SARAN}

\section{Simpulan}

Berdasarkan hasil analisis LQ pada tabel diatas selama periode 2010-2019 sektor pertanian di Kabupaten Tabanan masuk dalam kategori sektor unggulan, hal ini ditunjukan oleh rata-rata nilai Location Quotient (LQ) sebesar $1.52>1$. Artinya sektor pertanian ini tidak hanya mampu memenuhi kebutuhan di Kabupaten Tabanan tapi mampu juga memenuhi kebutuhan daerah lainnya. Hasil analisis shift share sektor pertanian di Kabupaten Tabanan masuk dalam kategori pertumbuhan wilayah lambat dan daya saing yang cepat yang ditunjukkan oleh nilai proportional shift yang negatif dan differential Shift yang positif.

\section{Saran}

Pemerintah Kabupaten Tabanan diharapkan dapat memanfaatkan dan lebih mengembangkan hasil produk pertaniannya, selain itu pemerintah Kabupaten Tabanan diharapkan bisa memberi perhatian dengan cara perbaikan infrastruktur dengan perbaikan sarana dan prasarana penunjang kegiatan basis yaitu seperti perbaikan jalan yang akan memudah pengangkutan barang dari satu daerah ke daerah yang lain di Kabupaten Tabanan. Disamping itu pemerintah dapat membuat program kebijakan yang sesuai dengan keadaan daerah serta memperhatikan sektor unggulan dalam melakukan perencanaan agar dapat meningkatkan pendapatan daerah.

Penelitian selanjutnya diharapkan dapat menganalisis menggunakan periode penelitian yang lebih panjang untuk mendapatkan gambaran yang lebih luas dan menambahkan analisis DLQ untuk dapat lebih mendekati kelemahan dari analisis LQ, agar dapat mengetahui peranan sektor prioritas masih atau tidak menjadi sektor basis dimasa yang akan datang.

\section{UCAPAN TERIMAKASIH}

Penulis mengucapkan terimaksih kepada pihak-pihak yang telah membantu dalam penelitian ini. Semoga penelitian ini dapat bermanfaat sebagaimana mestinya.

\section{DAFTAR PUSTAKA}

Ariyanto, D. C. (2013). Analisis Daya Saing sektor Unggulan Dalam Struktur Perekonomian Provinsi Jawa Tengah Tahun 2010.

Badan Pusat Statistik Kabupaten Tabanan. 2020. PDRB Seri 2010 Atas Dasar Harga Konstan Kabupaten Tabanan Menurut Lapangan Usaha (Juta Rupiah) 2010-2019.

Badan Pusat Statistik Jakarta Pusat. 2014. Potensi Pertanian Indonesia tahun 2013. Jakarta Pusat: Badan Pusat Statistik 
Badan Pusat Statistik Provinsi Bali. (2014). Produksi Padi Sawah dan Padi Ladang Kabupaten/Kota di Bali tahun 2013.

Badan Pusat Statistik Provinsi Bali. 2019. Laju Pertumbuhan Ekonomi/PDRB Kabupaten/Kota 2011-2019 (Persen).

Bank Indonesia. 2013. Kajian Ekonomi Regional Provinsi Bali.

Daryanto, A.2004. Keunggulan Daya Saing dan Teknik Identifikasi Komoditas Unggulan dalam Mengembangkan Potensi Ekonomi Regional. Jurnal Agrimedia. Vol 9. No. 2

Daryanto, A. (2009). POSISI DAYA SAING PERTANIAN INDONESIA DAN UPAYA PENINGKATANNYA Position of Agriculture Competitiveness in Indonesia and Its Efforts for Improvement.

De FRETES, P. N. (2017). Analisis Sektor Unggulan (Lq),Struktur Ekonomi (Shift Share), Dan Proyeksi Produk Domestik Regional Bruto Provinsi Papua 2018. Develop, 1(2). https://doi.org/10.25139/dev.v1i2.384

Hidayat, P., \& Si, M. (2004). ANALISIS DAYA SAING EKONOMI KABUPATEN BATU BARA Suci Ana Winta Ritonga Paidi Hidayat, SE, M.Si. 35, 323-334.

Iqbal, M. (2007). Analisis Peran Pemangku Kepentingan dan Implementasinya Dalam Pembangunan Pertanian. Jurnal Litbang Pertanian, 26(3), 89-99. http://pustaka.litbang.pertanian.go.id/publikasi/p3263071.pdf

Landoala, Tasrif. (2013). Potensi Pertanian Terhadap Pertumbuhan Ekonomi Indonesia.http://jembatan4.blogspot.com/2013/07/potensi-pertanian-terhadappertumbuhan.html?m=0. Diakses pada : 20 Juli 2020 